\title{
TUMORES EM CERTOS HÍBRIDOS DO GENERO NICOTIANA
}

\author{
F. G. Brieger \\ R. Forster
}

\section{INTRODUÇ $\widetilde{A} O$}

Kostoff (9) foi o primeiro a descrever a formação de tumores ou outras malformações em híbridos interespecíficos do gênero Nicotiana. Depois alguns outros autores se ocuparam com este fenômeno, e podemos tirar dos seus trabalhos duas conclusões:

a) Todos observaram estas anormalidades nos mesmos híbridos, especialmente em $N$. glauca $\times$. Langsdorffii. Pelo fato, pois, de que aparecem sempre nestes, e nunca nas espécies puras nem na maioria dos outros híbridos interespecíficos do gênero, e, ainda mais, independente até do continente no qual os estudos foram realizados, parece definitivamente excluida a possibilidade de uma origem patogênica, provocada por fungos ou bactérias.

b) Nenhum autor até agora foi capaz de propor uma explicação satisfatória para a origem dos tumores, sendo que nenhuma das várias especulações até hoje publicadas pode ser comprovada. Assim Kostoff atribuiu inicialmente $(9,10)$ a origem dos tumores a uma incompatibilidade entre as espécies cruzadas e às reações imunológicas por ela provocadas. Depois, sem explicar as suas razões, Kostoff (11) mudou de opinião e considerou como causa as mutações somáticas. Finalmente $(12,13)$, fala de uma falta do balanço gênico depois de uma troca somática de partes de cromosômios não homólogos. Whitaker (16) atribuiu principal importância ao citoplasma, mas visto que nestas combinações cruzamentos recíprocos não podem ser feitos e estudados, a hipótese não pode ser comprovada nem desprovada.

Praticamente só se observaram tumores em híbridos nos quais representantes do grupo $\mathrm{n}=9$ cromosômios foram usados. A reação foi bastante forte nos experimentos de Kostoff (9), quando $N$. Langsdorffii

(") Da Escola Superior de Agricultura "Luiz de Queiroz". 
o foi cruzado com $N$. glauca, $N$. rustica e $N$. paniculata e, por outro lado, $N$. Sanderae ( ${ }^{*}$ ) (ou alala) ot com $N$. tabacum e $N$. rustica. É bem interessante que, de acordo com este autor, $N$. glauca x $N$. Sanderae não exibiu anormalidades. Uma reação fraca e, a nosso ver duvidosa, foi descrita para o híbrido: $N$. rustica $\times$. tabacum (9).

Observamos tumores nos híbridos $N$. rustica $\times N$. Langsdorffii, mas o principal material são os híbridos $N$. glauca $q$ cruzados com N. Langsdorffii, N. Sanderae e com híbridos (Tangsidorffii x Sanderae $\mathrm{F}_{1}$ ). Quando, de modo geral, apenas verificamos as observações já publicadas dos autores, dois pontos nos pareceram novos. Vamos, pois, aquí descrevê-los.

\section{DIFERENÇA MONOFATORIAL ENTRE $N$. LANGSDORFFII $E$ N. SANDERAE}

A reação dos híbridos de $N$. glauca com $N$. Langsdorffii, de um lado, e N. Sanderae, de cutro, é bastante diferente.

a) $N$. glauca $\times$ N. Tiangstorffii. $\bigcirc$ comportamento dos nossos híbridos está em todos os detalhes, de acordo com o descrito por outros autores. Exceto o aparecimento de tumores, muitas vezes bem grandes, no colo da raiz, e de pequenos crescimentos nas próprias raizes, as plantas ficaram bem normais durante os primeiros meses. Formava-se uma roseta a depois uma haste principal, que terminava com a inflorescência (fig. 1 e 2).

Nas partes já completamente formadas aparecem tumores. Estes não são linitados aos niós, mas em escala menor aparecem tambem nos internódios (fig. 10), onde são externamente cobertos com suber, que lhes dá cor marrom. Os tumores dos nós, mesmo em inflorescências bastánte velhas (fig. 9), podem tornar-se grandes, e deles podem sair uma ou mais hastes, que são perfeitamente normais (fig. 8). Tentamos provocar un enraizamento de tais brotos, mas sem sucesso. Os tumores no colo da raiz são verdes e produzem geralmente brotos curtos e irregulares, com folhas anormais (fig. 7).

Nas raizes são brancos ou amarelo-marrons quando escondidos na terra ; tornam-se, porem, verdes, quando expostos à luz.

Em alguns indivíduos velhos, apareceram tumores tambem nas folhas. As flores sempre foram absolutamente normais.

(*) Usamos aquí a denominação $N$. Sanderae, que inclue todas as formas usadas, muitas vezes denominadas $N$. affinis, $N$. alata e $N$. forgetiana. 
b) $N$. glauca $\times N$. Sanderae. $\bigcirc$ comportamento é bastante diferente do dos híbridos descritos acima. Os tumores no colo da raiz aparecem até mais cedo e desenvolvem-se mais.

De modo geral, temos que distinguir duas formas de reação. No primeiro caso os tumores no colo cresceram enormemente e as plartas ficaram pequenas e raguíticas (fig. 5). Estes podem finalmente produzir brotos numerosos e normais (fig. 11 e 12).

No segundo caso, o crescimento da haste foi muito vigoroso, mostrando, porem, uma ramificação perfeitamente anormal. Os galhos laterais não cresceram apenas quando a planta iniciou a florada, mas desde o início. Alem disso, em vez de um galho por axila, desenvolveuse grande número de gemas seriadas ("seriale Beiknospen"), como bem ilustram as figuras 3 e 4 .

As folhas, igualmente numerosas nos diferentes galhos, foram sempre mais ou menos deformadas, sem produzir tumores.

As flores tambem foram anormais, com protuberâncias e outras irregularidades de forma, e de cor sempre manchada.

c) $N$. glauca $\times\left(N\right.$. Langsdorffii $\times 1$. Sanderae $\mathrm{F}_{1}$ ). Os mesmos tipos profundamente diferentes dos cruzamentos entre duas espécies reaparecem no cruzamento das três espécies. Mas o fator mais importante era que praticamente todos os indivíduos podiam ser classificados e atribuidos a um ou outro dos dois tipos: o dos híbridos $N$. glauca x $N$. Langsdorffii ou $N$. glauca $\times N$. Sanderae. $O$ número de plantas não foi muito grande, mas podia-se verificar que a frequência dos dois tipos foi aproximadamente a mesma. Daí podemos concluir que eles são causados por dois gens aleles. As espécies puras são homozigotas, de modo que os híbridos simples são uniformes no seu comportamento. Mas cruzando $N$. glauca com o polen do híbrido $N$. Langsdorffii $\mathrm{x}$ $N$. Sanderae, obtemos uma segregação típica de um "backross" monofatorial, isto é, $\frac{1}{2}: \frac{1}{2}$.

As duas espécies $N$. Langsdorffii e $N$. Sanderae são bastante relacionadas. Teem o mesmo número de cromosômios $(n=9)$, o pareamento nos híbridos é completo, com 9 bivalentes na meiose e a segregação é perfeitamente normal. Um número de diferenças interespecíficas tem base genética bem simples, como a coloração das flores e do polen, a auto-esterilidade, etc. Anderson e de Winton (1), Brieger (4, 5), East (6, 7) e Skalinska (15). 
Oefeito dos aleles que alteram o porte dos híbridos quando cruzados com $N$. glauca não é visivel nem nas espécies $N$. Langsdorffii e $N$. Sanderae nem nos seus híbridos. $\bigcirc$ seu efeito é assim completamente recessivo-hipostático. Somente quando combinado com os gens de $N$. glauca é que se manifesta. Isto não é novidade. A segregação de um fator semelhante foi observada por Brieger (3) nos cruzamentos entre $N$. longiflora x $N$. Sanderae. Na maioria dos cruzamentos, as plantas $F_{1}$ foram fortes e normalmente desenvolvidas. Mas sempre quando um certo indivíduo de $N$. longiflora foi usado, a geração $F_{1}$ foi ditípica : metade das plantas foi forte e normal e metade foi muito fraca. Um caso semelhante foi tambem encontrado por Hollingshead (8) em Crepis teclorum.

A diferença entre o caso relatado neste trabalho e os diversos casos justamente citados é a səguinte: nestes últimos manifesta-se um gen que apənas está presente em alguns indivíduos, quando no caso məncionado na presente publicação sə trata de dois aleles que se enco.tram em forma homozigota, cada um em uma das duas espécies.

É interessante notar que as duas espécies parentes tambem se comportam diferentemente em cruzamentos com $N$. paniculata. Brieger (3) observou que os híbridos $N$. paniculata $\times N$. Langsdorffii são səmpre muito fracos e morrem quando ainda pequenos e jovens, enquanto que os híbridos $N$. paniculata x $N$. Sanderae chegam até ao florescimento. Seu desenvolvimento, entratanto, é sempre bem anormal, como demonstram as fotografias na citada publicação. Kostoff (9) encontrou muitos tumores nas raizes e hastes de $N$. paniculata $\mathrm{x} N$. Langsdorffii, poucos nas raizez e nenhum nas hastes de $N$. paniculata x $N$. Sanderae. Não podemos decidir se estas diferenças são provocadas pelos mesmos gens, como no caso dos híbridos com $N$. glauca, já relatado.

Demonstramos que existem dois gens aleles, um para cada espécie $N$. Langrdorffii e $N$. Sanderae, que alteram o curso do desenvolvimento nos híbridos com $N$. glauca. Disso não podemos concluir que sejam responsaveis pelas anormalidades, formação de tumores, etc. Trata-se, naturalmente, de uma possibilidade. Estes gens podem ser, de-fato, os determinadores da formação dos tumores e outras malformações, ou podem ser apenas modificadores de um desenvolvimento anormal, provocado por outros agentes.

\section{ONTOGENIA E HISTOLOGIA DOS TUMORES}

Kostoff (9) deu alguns pormenores sobre a histologia dos tumores e Levine (14) publicou uma descrição mais ampla. Este último autor 
demonstrou que os tumores espontâneos dos híbridos são estruturalmente diferentes dos tumores ou "crown galls" causados pelo Bacterium tumefaciens. Mas parece que falta uma descrição da ontogenia dos tumores nas hastes.

De acordo com as nossas observações, o primeiro sinal da formação de um tumor é o aparecimento de células necróticas na região do cortex primário, entre a epiderme e o colênquima. As células sãs, adjacentes, reagem do modo típico à reação contra uma irritação traumática, como, por exemplo, a descrita por Brieger (2). Casos idênticos aos apresentados nas figuras 2 e $4(\mathrm{Abb} 1)$ desse trabalho, podem ser vistos com frequência nas fases iniciais da formação dos tumores. Das duas reações traumáticas descritas por Brieger (2), a fase do crescimento é inicialmente mais forte no primeiro estágio da formação dos tumores. Posteriormente, tambem ocorrem muitas divisões de células.

Com o tempo, a região afetada se estende. A epiderme e todas as camadas do lado de fora das células ativadas degeneram e morrem, e os tecidos internos do cortex são finalmente atingidos pela ativação. Assim, já se formam tumores grandes, mas sem ligação com o tecido do cilindro central. Aparecem nos tumores tambem certas diferenciações celulares. A sua superfície é formada por células pequenas, de um verde forte e aparecem tambem séries de traqueides traumáticas (fig. 13).

Mais tarde o câmbio e o xilema são atingidos. A fase inicial é ilustrada nas figuras 13 e 15. As divisões no câmbio não seguem mais a orientação tangencial e os raios medulares secundários começam a crescer e alongar-se. As figuras 13 e 14 demonstram que a atividade do câmbio não foi regular anteriormente. $O$ xilema não forma um cilindro de grossura uniforme. Em partes das secções mostradas, umas regiões apresentam o dobro do diâmetro do xilema de outras.

Finalmente tambem a medula é atingida, o cilindro do xilema abrese (fig. 14) e se estabelece uma perfeita ligação com os tumores.

Assim a origem dos tumores nas hastes é perfeitamente endógena. Forma-se, porem, um meristema superficial e bastante irregular (fig. 13 e 16). A observação microscópica demonstrou que em alguns lugares este meristema pode finalmente voltar à normalidade e formar pontos vegetativos e hastes normais. O lugar indicado por flecha, na figura 14, talvez corresponda a um tal ponto vegetativo normalizado.

O ponto mais importante da ontogenia dos tumores parecenos ser a sua origem endógena de tecidos maduros e não meristemáticos. Não podemos estar absolutamente certos de que a necrose de algumas células seja de-fato o início, ou se algumas células começarn a crescer, prejudicando as vizinhas e causando a sua degeneração. É certo que mais tarde, quando o cresci- 
mento já atinge um maior número de células e mais camadas, esta ativação das células não é mais dependente do contacto com focos necróticos.

\section{INCLUSÕES NAS CÉLULAS}

Desejamos descrever aquí uma observação, embora sem podermos ainda interpretá-la. Nas primeiras fases da formação dos tumores, quando são ativadas células do cortex primário, encontramos səmpre inclusões em células vizinhas, que não foram ativadas. Como demonstra a figura 17, trata-se de corpos redondos com uma membran e um conteudo incolor, de alto poder de refração e que enche irregularmente o interior do corpo, deixando vacúolos ainda pequenos, que são com mais frequência encontrados nas células do cortex. Não tendo estas participado ativamente da formação dos tumores, são mais tarda eliminadas em consequência da origem endógena do tumor.

As inclusões semelham células de certos fungos, por exemplo, de Chytridiales. Não podemos afirmar, entretanto, que se trate efetivamente de tais células.

Queremos apenas registar a ocorrência destas inclusões, que não encontramos nos tecidos das espécies puras, mas somente nos híbridos que formam os tumores. A relação entre elas e o tecido anormal é ainda obscura.

\section{CONCLUSÕES}

Não temos a intenção de discutir as especulações já formuladas por vários autores, e que mencionamos rapidamente na introdução.

É evidente que a constituição genética é um ponto essencial. Nenhuma espécie pura nem a maioria dos híbridos de espécies no gênero Vicoliana demonstra as anormalidades descritas. São encontradas apenas em alguns híbridos de espécies do grupo com $\mathrm{n}=9$, isto é, $N$. Langsdorffii e $N$. Sanderae, com suas muitas formas, com outras espécies, especialmente $N$. glauca.

É provavel que as anormalidades sejam provocadas por qualquer desarranjo fisiológico e não por uma infeção específica.

$O$ efeito de gens específicos que foram identificados tambem não ajuda na solução do problema, porque não podemos dizer se eles são determinadores das anormalidades ou apenas modificadores de processos fisiológicos causados por outros agentes.

A origem endógena em tecidos maduros exclue a possibilidade de que anormalidades nas divisões mitóticas possam ser a causa direta da formação de tumores.

Chegamos então à conclusão de que a etiologia dos tumores espontâneos e das outras anormalidades descritas continua a ser desconhecida. 


\section{SUMMARY}

The present paper gives some observations on the tumour formation and other abnormalities observed in the interspecific hybrids, Nicotiana glauca $\times N$. Langsdorffii and $N$. glauca $\times N$. Sanderae. Without entering into a detailed discussion of the literature and the various speculations proposed by Kostoff and Whitaker about the causes of tumour formations or on the relations between "spontaneous" and pathogenic tumours (Kostoff, Levine and others), two new observations are described.

1) The abnormalities in the two above mentioned hybrids are quite different.

As already reported by other authors, the hybrids $N$. glauca $\times N$. Langsdorffii are initially quite normal and vigorous, while tumours and other proliferations, on the stem, the stem base and the root appear more or less frequently in older plants. Tumours on leaf are rare and flowers are normal (fig. 1,2,7 and 10).

The hybrids $N$. glauca $\times$. Sanderae are very different from the former. These remain either weak and rachitic, forming early large tumours at the stem base and on the root (fig. 5 and 6 right half). Numerous shoots with more or less normal leaves may arise from these tumours (fig. 11 and 12). Or the plants show an extremely vigorous and abnormal ramification with a number of serial axial shoots developing in each leaf axis (fig. 3 and 4). The leaves are frequently deformed and the flowers exhibit abnormally coloured patches.

When crossing $N$. glauca with Fl ( $N$. Langsdorffii x $N$. Sanderae) the offspring could clearly be divided into two groups: plants exactly as described for $N$. glauca $\mathrm{x}$ $N$. Langsdoryfii and others which correspond to the types of $N$. glauca $\times N$. Sanderae. Thus it seems that we are dealing with a monogenic differences, each species, $N$. Langsdorffii and $N$. Sanderae, being homozygous for one allele each. These alleles have no phenotypic effect in either pure species, but only in hybrids when combined with the genom of $N$. glauca.

The situation is somewhat similar to the sublethal genes reported in interspecific crosses involving $N$. longiflora (Brieger, 3) and Crepis tectorum (Hollingshead, 8).

Since the hybrids with $N$. glauca are completely sterile, it cannot be decided whether the genes reported are only modifiers or are actually causing the tumour formation and the other abnormalities.

2) A histological study was made about the origin of stem tumours. The first sign is the activation of cells of the tissues between epidermies and collenchyma. Some cells adjoining other which are dead or dying start to grow and later on to divide, in the manner typical for cells under the action of traumatic hormons (cf. Brieger, 2). Later on the whole region is activated and the cortex layers degenerate. At this stage large tumours may be formed, but as yet without connection with the xylem (fig. 15). Later on the cambium and the secundary medulary rays participate in the irregular development (fig. 13) which finally reaches the medulla. Finally the central cylindre is forced open and the tumours connected with it (fig. 14).

Thus tumours formation on the stem is endogeneous and starts from mature cells, not from meristematic cells.

3) Finally an observation is reported, without an attempt to explain it. In the earliest phases of tumours formation in the stem and in cells not participating it, intracellular bodies are observed (fig. 17) with a colourless membrane and on alveolar and highly refractive content. These bodies resemble somewhat cells of fungus such as Chytridiales, but, as already said, their nature is obscure. 


\section{LITERATURA CITADA}

1. Anderson, E. and D. de Winton. The genetic analysis of an unusual relation between self-sterility and self-fertility in Nicotiana. Ann. Miss. Bot. Gard. 18:97-116. 1931.

2. Brieger, F. G. Untersuchungen ueber den Wundreiz. Ber. Deuts. Botan. Gesel. 52:79-90, Abb. 1.2. 1925.

3. Brieger, F. G. Vererbung bei Artbastarden unter besonderer Beruecksichtigung der Gattung Nicotiana. Der Zuechter 1:140-152, Abb. 1-11. 1929.

4. Brieger, F. G. Untersuchungen an den Bastarden der Arten Nicotiana Sanderae, $N$. Lang.rdorffii und $N$. longiflora. Zeits. Indukt. A.bst. und Vererb. 54:235-239. Tab. 1. 1930.

5. Brieger, F. G. Genetic analysis of the cross between the self-fertile Nicotiana Lang.sdorffii and the self-sterile N. Sanderae. Jour. Genetics 30:79-100, fig. 1-2, Tab. 1-10, 1935.

6. East, E. M. Inheritance in crosses between Nicotiana Langrdorffii and $N$. alata. Genetics 13:311-333. 1916.

7. East, E. M. Studies on self-sterility. IX. The behaviour of crosses between self-sterile and self-fertile plants. Genetics 17:175-202. 1932.

8. Hollingshead, L. A lethal factor in Crepis effective only in an interspecific hybrid. Genetics 15:114-140. 1930.

9. Kostoff, D. Tumors and other malformations on certain Nicotiana hybrids. Zentral. Bakt. Parasit. Infekt. 2:244-260, fig. 1-18, tab. 1-3. 1930.

10. Kostoff, D. Tumor in the light of researches on plant tumors and galls and its relation to the problem of mutation. (A critical review from biophysical, biochemical and cytogenetical point of view.) Protoplasma 20:440-456. 1933.

11. Kostoff, D. Heritable tumors in plants expərimentally produced. Genetics 17:367-376, fig. 1-3. 1935.

12. Kostoff, D. Abnormal mitosis in tobacco plants forming hereditary tumours. Nature 144:599. 1939.

13. Kostoff, D. Studies on atypical growth in plants from a cytogenetic point of view. Jour. Genetics 39:469-484, pl. VIII, fig. I-8. 1940.

14. Levine, M. Tumors of tobacco hybrids. Amer. Jour. Bot. 24:250-256, fig. 1-17. 1937.

15. Sachs-Skalinska, M. Contribution à l'analyse génétique de la forme de la corolle du genre Nicotiana (Polish, French summary). Kosmosu 47:255-273. 1921.

16. Whitaker, Thomas $W$. The occurrence of tumors on certain Nicotiana hybrids. Journ. Arnold Arboretum 15:144-153, pl. 90, fig. 1. 1934.

\section{EXPLICAÇ̃̃O DAS FIGURAS}

Figura 1. N. glauca x N. Langsdorffii (N1025). Planta em início de florescimento, sem tumores ainda.

Figura 2. A mesma planta da figura 1, mostrando disposição das ramificações.

Figuras 3 e 4 . Planta do tipo $N$. glauca $\times N$. Sanderae no cruzamento $N$. glauca $\times$ (N. affinis $\times$ N. Langsdorffii $\mathrm{F}_{1}$ ), (N. 1029) mostrando numerosas ramificações, desde o colo da planta. 
Figura 5. Duas plantas da mesma família (N1029) mostrando a segregação no porte: no lado esquerdo (2N) planta do tipo $N$. glauca $\times N$. Langsdorffii $\theta_{1}$ no direito (1N), planta do tipo $N$. glauca x $N$. Sanderae.

Figura 6. Colos das duas plantas da figura 5. A planta (lN) mostra o tumor precoce.

Figura 7. Tumores no colo e nas raizes de uma planta no cruzamento $N$. glauca $\times N$. Langsdorffii.

Figura 8. N. glauca x N. Langsdorffii. Tumor na inflorescência, apresentando forte brotąão.

Figura 9. $N$. glauca × $N$. Langsdorffii. Inflorescência mostrando numerosos tumores em os nós.

Figura 10. $N$. glauca $\times$ N. Langsdorffii. Tumores dos nos e internódios.

Figura 11. Planta jovem do tipo $N$. glauca $\times N$. Sanderae no cruzamento $N$. glauca $\times$ $\left(N\right.$. affinis $\times N$. Langsdorffii $\mathrm{F}_{1}$ ) mostrando tumores com grande número de brotos.

Figura 12. A mesma planta da figura $11 \mathrm{com}$ detalhe do colo $\theta$ raiz.

Figuras 13 a 16. Cortes transversais em hastes de híbridos $N$. glauca $\times N$. Langsdorffii mostrando tumores em diferentes idades. Na figura 14 a flecha indica a formação de um ponto vegetativo. Na figura 16 a flecha indica a parte da haste principal s6 parcialmente visivel.

Figura 17. Parte do cortex primário da parte externa do colênquima num corte transversal, no híbrido $N$. glauca $\times N$. Langsdorffii. A célula indicada pela flecha contem uma inclusão indeterminada. 


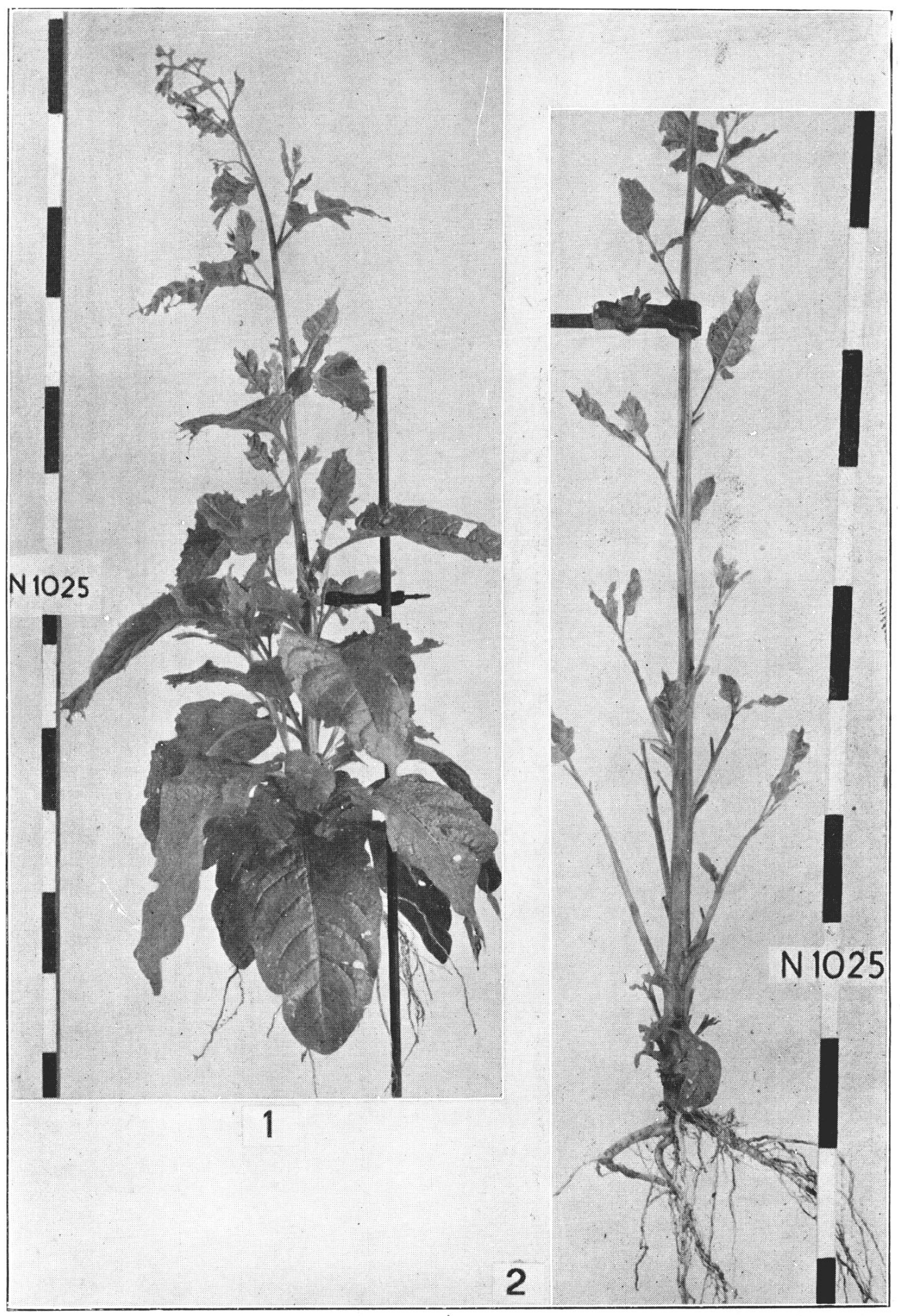




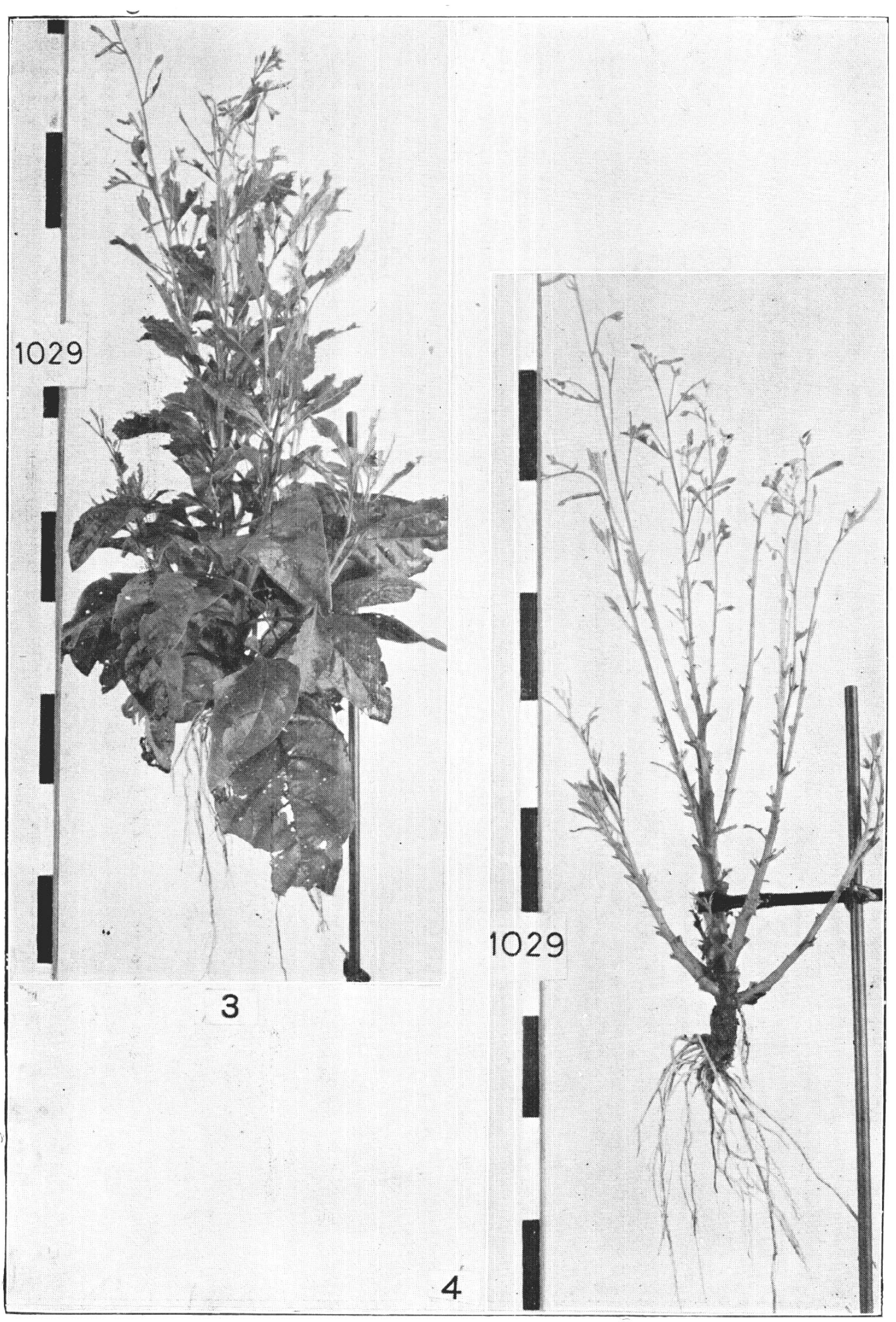




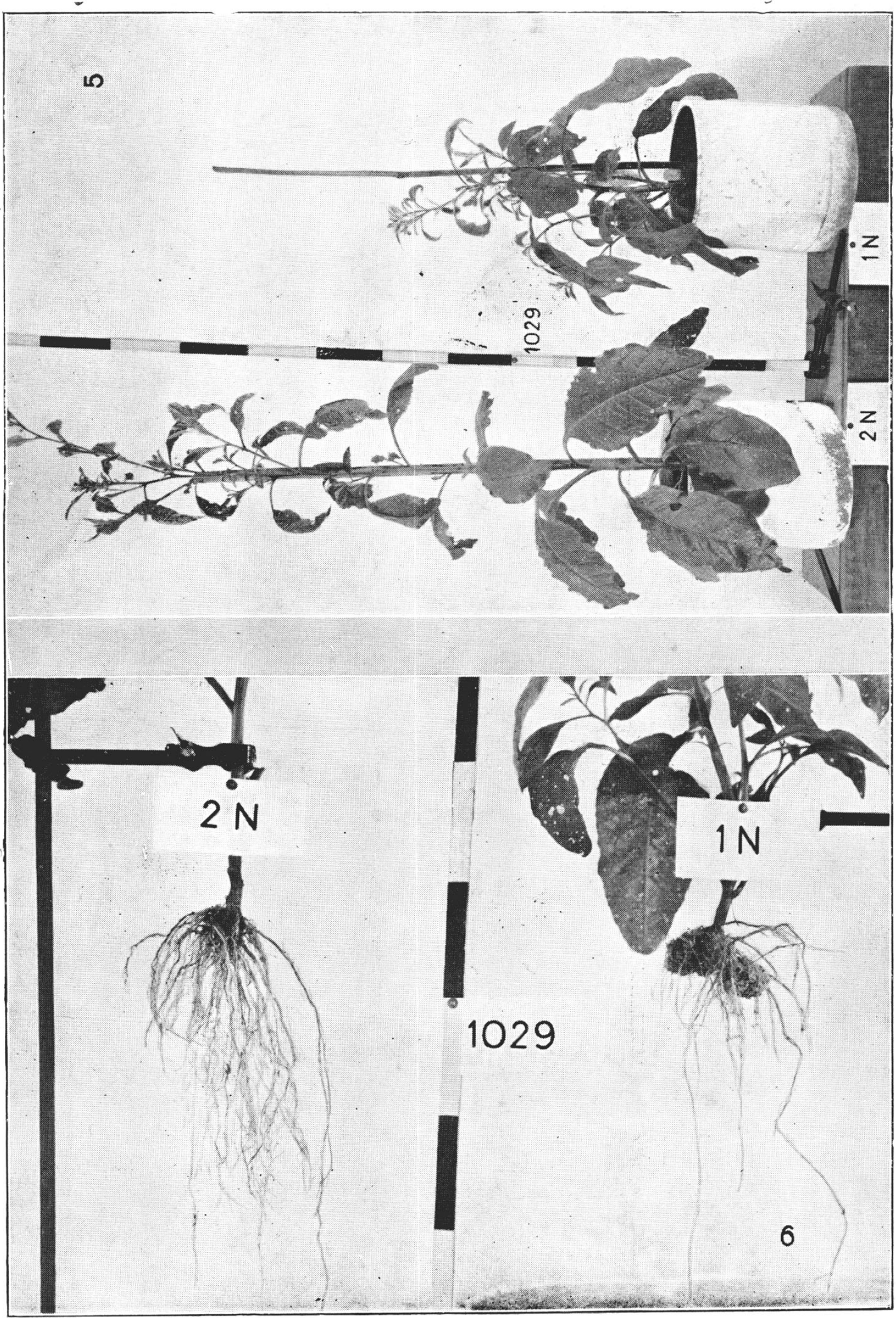




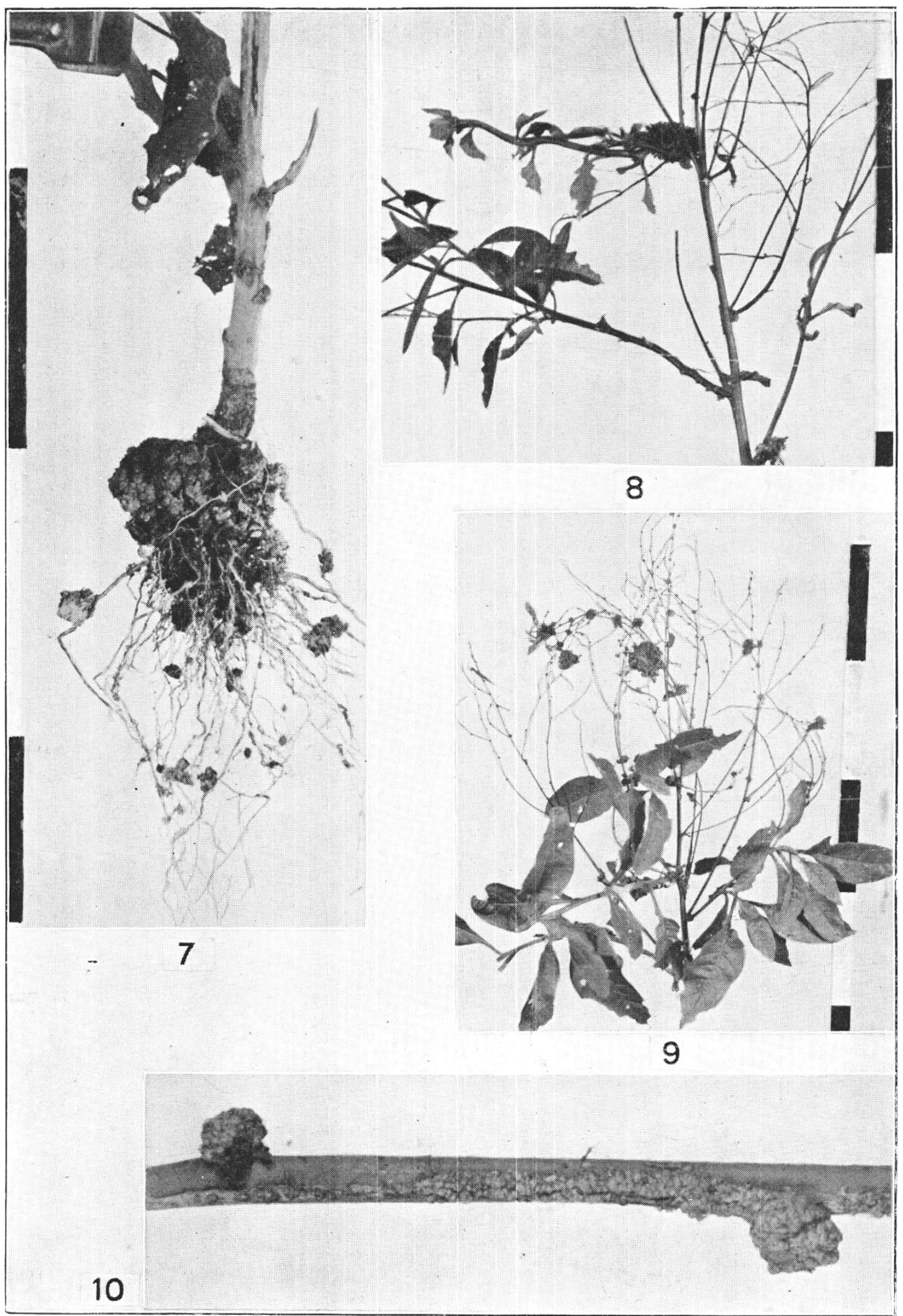


i i i

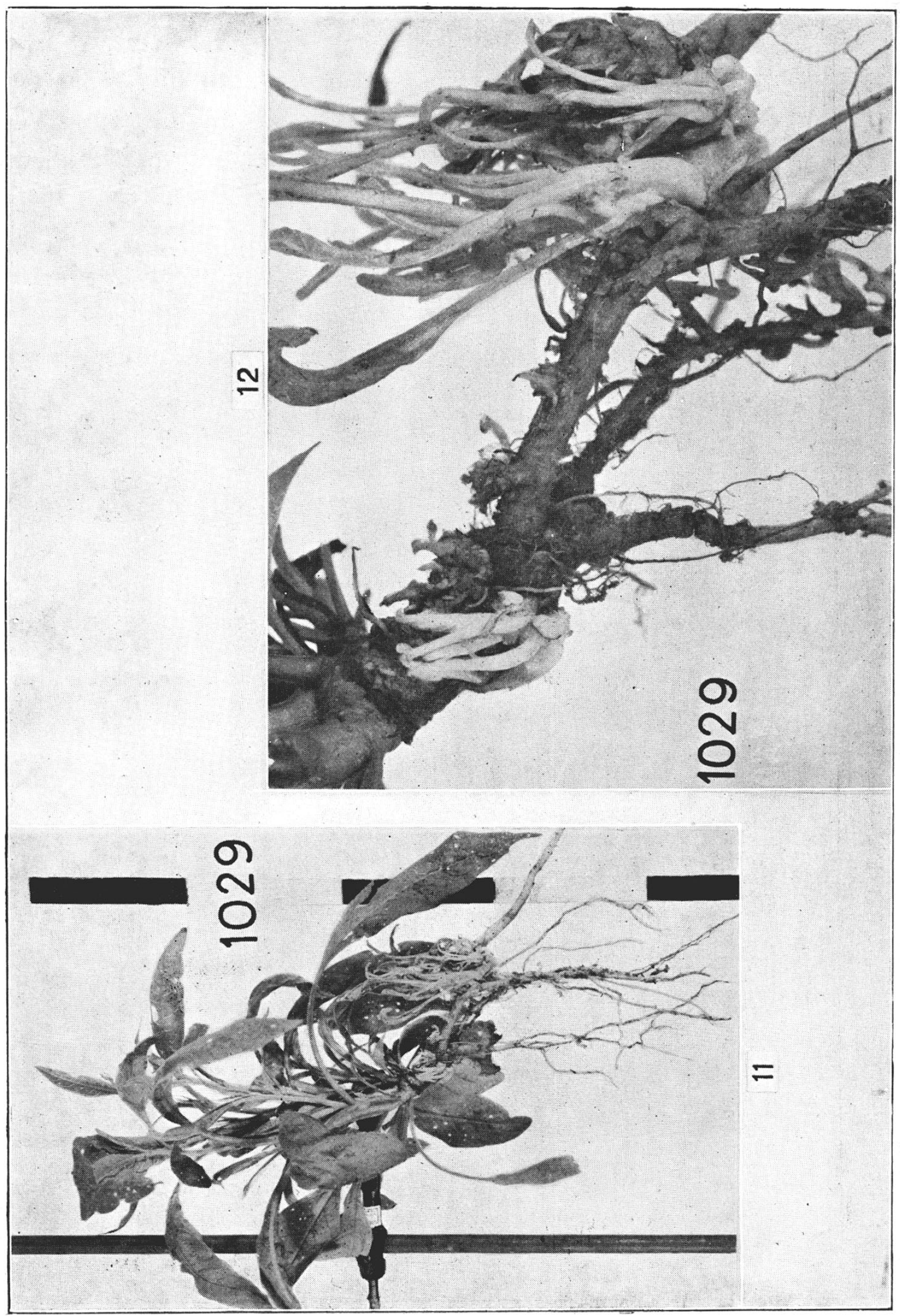




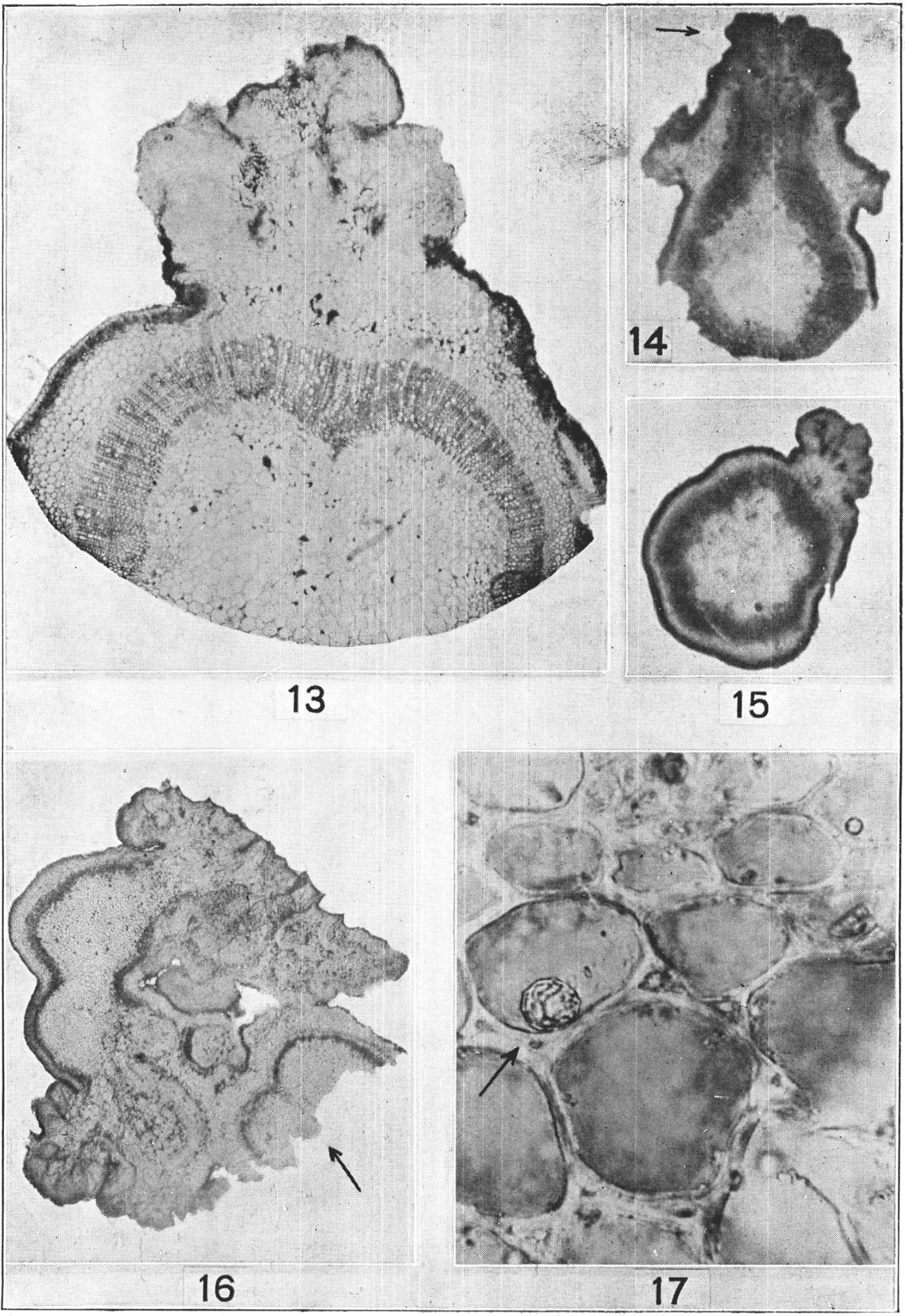

